\title{
ETANOL E USO CORPORATIVO DO TERRITÓRIO
}

\author{
ethanol and corporative use of territory
}

\author{
João Humberto Camelini* \\ Ricardo Castillo**
}

\section{Resumo}

O trabalho apresenta alguns aspectos históricos da ocupação canavieira no Brasil, procurando demonstrar, em linhas gerais, como se construiu sua configuração atual. Com o objetivo de favorecer a compreensão da dinâmica da ocupação do território pelo setor sucroenergético, o texto evidencia os critérios utilizados na escolha de novas áreas para a atividade e avalia as principais implicações decorrentes deste processo de expansão na escala local, apontando uma relação, aparentemente contraditória, entre a existência de competitividade regional diferenciada para a produção de etanol e o eventual estabelecimento de quadros de vulnerabilidade territorial.

Palavras-chave: Etanol, Competitividade Regional, Vulnerabilidade Territorial, Cerrado.

\begin{abstract}
This paper presents some historical aspects of the sugarcane occupation in Brazil, trying to demonstrate, in general, as they built the current reality. Aiming to promote understanding of the dynamics of territory occupation by the sugarcane industry, the text shows the criteria used in selecting new areas for activity and discusses the main implications of this expansion process at the local scale, indicating an apparently contradictory relationship between the existence of superior regional competitiveness for the ethanol production and the eventual establishment of territorial vulnerability conditions.
\end{abstract}

Key words: Ethanol, Regional Competitiveness, Territorial Vulnerability, Cerrados.

\section{Resumen}

Este artículo presenta algunos de los aspectos históricos de la ocupación de caña de azúcar en Brasil, con el fin de mostrar cómo se construyó la realidad actual. Con el objetivo de promover la comprensión de la dinámica de ocupación del territorio por la industria de la caña de azúcar, el texto muestra los criterios utilizados en la selección de nuevas áreas de actividad y se analizan las principales implicaciones de este proceso de expansión a escala local, lo que indica una relación aparentemente contradictoria entre la existencia de competitividad regional superior para la producción de etanol y el eventual establecimiento de condiciones de vulnerabilidad territorial.

Palabras claves: Etanol, Competitividad Regional, Vulnerabilidad Territorial, Cerrado.

(*) Msc. João Humberto Camelini. Doutorando no Programa de Pós-Graduação em Geografia da Universidade Estadual de Campinas, Cx. Postal 6152, CEP: 13.083-970, Campinas (SP), Brasil. Tel: (+55 19) 91333381 - joao.camelini@ige.unicamp.br.

(**) Bolsista Produtividade do CNPq e Prof. Dr. do Programa de Pós-Graduação em Geografia da Universidade Estadual de Campinas, Cx. Postal 6152, CEP: 13.083-970, Campinas (SP), Brasil. Tel: (+55 19) 35215114 - castillo@ige.unicamp.br 


\section{INTRODUÇÃO}

A importância do etanol na economia brasileira aumentou substancialmente na última década. Sua consolidação no mercado interno, associada à crescente expectativa pela evolução de seu consumo no exterior, fizeram do investimento no setor sucroenergético um grande negócio para grupos nacionais e estrangeiros, que lançam mão de estratégias agressivas para expandir a produção. Tais demandas impulsionam a desconcentração espacial produtiva, ainda que o epicentro do setor, as indústrias de bens de capital e a origem de grande parte dos investimentos, da pesquisa científica e das tecnologias permaneçam em terras paulistas.

Do ponto de vista corporativo, a expansão da produção do etanol para novas áreas implica na necessidade de identificar os municípios mais adequados ao estabelecimento desta atividade, o que exige certa obediência a um conjunto de critérios de escolha. Trata-se, portanto, da seletividade espacial em busca do aumento de competitividade, principal diretriz dos agentes capitalizados envolvidos no processo. As facilidades oferecidas pelo Estado, em estreita cooperação com as grandes empresas, fazem parte do conjunto de variáveis que pautam as localizações dos investimentos, notadamente em usinas.

Diante do quadro brevemente descrito acima, este trabalho busca compreender, em linhas gerais, a dinâmica de expansão do setor sucroenergético no território brasileiro e algumas implicações do encontro entre, de um lado, a agricultura intensiva e a agroindústria moderna e, de outro, as áreas até pouco tempo atrás ocupadas por pastagens, culturas comerciais ou pela pequena produção familiar. Tal estudo tem como objetivo principal fornecer subsídios que, aliados a colaborações de outros pesquisadores, permitam compor uma proposta metodológica para análise geoespacial da vulnerabilidade territorial associada à expansão do setor sucroenergético no Brasil, o que representaria uma importante ferramenta auxiliar para a elaboração de políticas públicas centradas na preservação dos interesses das populações locais, isto é, dos municípios que abrigam o cultivo e a industrialização da cana-de-açúcar. Com esta finalidade, os procedimentos adotados até o momento incluem o mapeamento da estrutura topológica ligada à circulação do etanol no território, trabalhos de campo buscando identificar a área de atuação e potencial de influência regional das unidades de produção, análise de critérios para a identificação de propensão à fragilização local e cruzamentos entre dados de fontes oficiais para comprovação sistematizada das tendências empiricamente observadas.

Este artigo está organizado em três partes. A primeira procura evidenciar alguns aspectos históricos de grande importância na construção da atual realidade da ocupação sucroenergética no Brasil, possibilitando compreender como o etanol adquiriu status de produto estratégico, o que implica, também, em identificar as formas com que o Estado atuou na regulação da sua produção e comercialização nos diferentes períodos históricos. Em seguida, são expostos alguns dos principais critérios de seletividade espacial que determinam a forma com que se desenvolve o atual processo de expansão desta atividade no país, resultando na formação de um novo polo produtivo no Cerrado. Por fim, discute-se como, em muitos casos, a emergência de regiões competitivas do etanol pode ocasionar graves implicações sociais e ambientais nos municípios, contradizendo interpretações segundo as quais o crescimento econômico atrelado à instalação de uma usina de processamento de cana-de-açúcar traz consigo o "desenvolvimento".

Partimos do pressuposto de que a competitividade não é um atributo ou qualidade apenas dos agentes ou das atividades econômicas no período histórico atual. Ao contrário do que propõe Cano (2007), a competitividade designa também uma condição regional, tornando-se a característica principal de algumas regiões produtivas (Santos, 1988), através de combinações particulares de elementos materiais (naturais e técnicos) e normativos (principalmente benefícios fiscais), e permitindo maiores rendimentos para determinados setores ou subsetores econômicos. Denominamos essas frações do espaço nacional, cuja coerência se estabelece pela extrema especialização produtiva, tanto no campo quanto na cidade, de regiões competitivas (CASTILLO; FREDERICO, 2010a). 


\section{UMA BREVE PERIODIZAÇÃO DO SETOR SUCROENERGÉTICO}

A colonização do Brasil foi impulsionada e economicamente sustentada, em grande medida, pela monocultura canavieira destinada à produção de açúcar. Este modelo de ocupação viabilizou, especialmente no início do período colonial, a exploração lucrativa das terras férteis e abundantemente disponíveis, tendo em vista que a comercialização desta especiaria no mercado europeu havia se revelado um excelente negócio para a Coroa portuguesa. E foi graças à proximidade com este grande centro consumidor que as lavouras de cana-de-açúcar primeiramente se instalaram no Nordeste brasileiro, de onde o transporte do produto final poderia ser realizado com relativa facilidade. Deste modo, mesmo diante das crises cíclicas que caracterizaram esta atividade ao longo de toda a História, ela sempre teve importância estratégica no direcionamento das políticas públicas brasileiras.

Originado de uma variante do processo produtivo açucareiro, o álcool esteve inicialmente - e por muitos anos - numa posição de menor importância econômica, meramente complementar, já que sua produção servia apenas para dar vazão à matéria-prima excedente, gerando produtos de menor rentabilidade comercial quando o mercado do açúcar estava desaquecido. Uma exploração econômica mais consistente não foi identificada até o ano de 1925, que marcou a primeira iniciativa para elevar o status do álcool no cenário nacional, através da realização de um experimento relativamente bem sucedido, visando sua utilização como combustível veicular. Esta possibilidade de aplicação em larga escala, no entanto, permaneceu inexplorada diante das dificuldades técnicas, políticas e comerciais que não puderam ser superadas à época (MARCOLIN, 2008).

A condição estratégica do setor sucroalcooleiro tornou-se ainda mais evidente em 1933, quando foi criado o IAA (Instituto do Açúcar e do Álcool), com o intuito de proteger este segmento agroindustrial das oscilações do mercado externo, através do estabelecimento de cotas de produção, fixação de preços e outras medidas que evitariam também um colapso interno, decorrente da tendência ao aumento da produção paulista, cuja concorrência desarticularia completamente os usineiros nordestinos (PRADO JR, 1961). Assim iniciou-se um período duradouro de regulação, caracterizado por grande controle estatal.

Durante a segunda guerra mundial, a questão do deslocamento da produção para o Sudeste, especificamente para o estado de São Paulo, voltou à tona. Isto ocorreu porque os riscos envolvidos no tráfego de embarcações pela costa brasileira tornaram extremamente perigoso o transporte de açúcar do Nordeste para abastecer o mercado paulista, o que não deixou outra alternativa senão a consolidação de um novo polo de produção (SZMRECSÁNYI \& MOREIRA, 1991). A proximidade com o principal mercado consumidor, somada aos grandes aportes financeiros transferidos de outras atividades, resultou numa concentração espacial de usinas sem precedentes, que marcou o início de um novo momento da ocupação do território brasileiro pela cultura canavieira.

Anos depois, na década de 70, as sucessivas crises de abastecimento de petróleo estimularam a busca por alternativas que diminuíssem a dependência desta fonte de energia, o que levou ao surgimento do Proálcool (Programa Nacional do Álcool). Neste período, foram desenvolvidas soluções de engenharia mais consistentes e os produtores receberam subsídios, o que viabilizou a utilização do álcool hidratado como combustível em larga escala. A maturidade deste processo fez com que, na década seguinte, a indústria automotiva concentrasse suas energias na adoção do novo modelo, que passou a dominar o setor automotivo. O ápice desta predominância se deu em 1986, ano em que um número recorde de veículos leves movidos a álcool foi introduzido no mercado nacional. Nesta mesma época, porém, os preços do petróleo sofreram grande redução, órgãos influentes como o FMI e o Banco Mundial exerceram forte pressão e o Brasil tomou a decisão política de reduzir os benefícios concedidos aos produtores. Desta forma, a única alternativa encontrada foi direcionar a produção para o açúcar, o que resultou no gradual desabastecimento do mercado, culminando no momento mais crítico, ocorrido em 1989, quando o Proálcool foi oficialmente abandonado. 
Essa situação conduziu à modificação do modelo regulatório do setor sucroalcooleiro no Brasil, adaptando-o às circunstâncias do novo período histórico, dotado de características neoliberais. Fato emblemático desta guinada política foi a extinção do IAA em 1990, que marcou o início da desregulamentação do setor sucroalcooleiro. A partir daí, o controle sobre a produção foi atribuído à iniciativa privada, que responde diretamente às demandas do mercado. O Estado passou a atuar como indutor dos movimentos do setor, por meio de investimentos em infraestruturas de transporte, concessão de crédito e estabelecimento de políticas públicas compatíveis com as necessidades dos investidores, especialmente em relação à permissividade normativa, que facilita enormemente o uso corporativo do território (SANTOS, 2002).

A retomada do álcool como alternativa para o abastecimento veicular, porém, estava cercada de incertezas, já que a forma brusca com que ele foi retirado do mercado nacional gerou uma série de implicações traumáticas. A dependência exclusiva deste combustível era vista com restrições por usineiros, consumidores e pela própria indústria automobilística. Dentro deste contexto, passaram a ser empreendidos esforços no sentido de desenvolver uma tecnologia alternativa, que possibilitasse ao consumidor optar entre diferentes combustíveis no momento do abastecimento. Isto representaria uma poderosa ação de marketing para as montadoras, permitiria aos usineiros direcionar a produção livremente e atenderia às exigências do consumo. Foi assim que, em 2003, a tecnologia Flex Fuel tornou-se madura o suficiente para ser introduzida no mercado nacional, representando uma revolução sem precedentes, que mudaria os rumos da indústria do açúcar e do álcool. A partir deste ano, a maioria absoluta dos veículos leves comercializados passou a ser equipada com motores bicombustíveis, o que contribuiu para a consolidação do mercado interno e gerou um ambiente de grande confiança entre todos os agentes envolvidos.

Ao mesmo tempo em que o consumo nacional ganhou novo fôlego, mudanças no cenário político internacional resultaram em oportunidades para o setor. A busca por alternativas aos combustíveis fósseis tornou-se inevitável devido ao apelo ambientalista, à sua escassez anunciada e às complicações diplomáticas associadas ao controle da produção, que motivaram diversos conflitos nas últimas décadas (HARVEY, 2004). Assim, o potencial do mercado externo gerou enorme expectativa, que tornou muito promissor o investimento na produção de uma alternativa energética anteriormente testada em larga escala. Isto atraiu a atenção de grandes corporações altamente capitalizadas, nacionais e estrangeiras, capazes de realizar os investimentos necessários para produzir em quantidade compatível com a demanda futura. O álcool teve sua nomenclatura alterada para "etanol", devido a questões ligadas essencialmente a aspectos de marketing, o que levou o Brasil a se alinhar aos demais produtores mundiais. Também se tornou mais coerente adotar a terminologia "setor sucroenergético" em substituição a "setor sucroalcooleiro", numa referência à sua importância para a matriz energética, visto que, além da participação direta do etanol no abastecimento de veículos, secundariamente à sua produção é possível extrair a chamada "bioeletricidade", ou seja, eletricidade obtida por meio da biomassa do bagaço de cana.

\section{SELETIVIDADE ESPACIAL PARA A PRODUÇÃO DE ETANOL}

No sentido de viabilizar o incremento de produção diante das novas perspectivas de aumento da demanda, o número de usinas instaladas cresceu aceleradamente. Tendo em vista a concentração excessiva de unidades em terras paulistas, foi necessário encontrar alternativas que não impusessem grandes limitações ao escoamento da produção, intensificando assim o processo de desconcentração espacial iniciado na década de 90 . Esta necessidade implicou no estabelecimento de critérios para seletividade que, mapeados sob forma de camadas de informação espacialmente combinadas, permitem identificar as regiões com maior aptidão para este segmento agroindustrial, bem como aquelas onde há limitações importantes à sua instalação. Assim, compreendem-se como relevantes os critérios apresentados no quadro 1. 
Quadro 1 - Critérios de seletividade espacial do setor sucroenergético

\begin{tabular}{|c|c|}
\hline CATEGORIAS & CRITÉRIOS \\
\hline Físicos & $\begin{array}{ll}\text { - } & \text { Disponibilidade de terras agricultáveis; } \\
\text { - } & \text { Adequação dos solos às necessidades das plantas; } \\
\text { - } & \text { Existência de condições clinográficas adequadas; } \\
\text { - } & \text { Clima e disponibilidade hídrica. }\end{array}$ \\
\hline Econômicos & $\begin{array}{ll}\text { - } & \text { Custo da terra; } \\
\text { - } & \text { Estrutura para fornecimento de insumos e serviços; } \\
\text { - } & \text { Disponibilidade de força de trabalho. }\end{array}$ \\
\hline Infraestruturais Políticos & $\begin{array}{ll}\text { - } & \text { Boa condição logística; } \\
\text { - } & \text { Disponibilidade de variedades adaptadas; } \\
\text { - } & \text { Legislação ambiental com poucas restrições; } \\
\text { - } & \text { Restrições das áreas de plantio; } \\
\text { - } & \text { Vantagens decorrentes de benefícios fiscais. }\end{array}$ \\
\hline
\end{tabular}

Fonte: CAMELINI, 2011

A representação espacialmente combinada deste conjunto de critérios permite identificar impedimentos de maior relevância para o avanço das lavouras de cana e, consequentemente, para a produção de etanol. A disposição territorial de tais restrições pode ser observada na figura 1 .

Através deste mapeamento, é possível observar que as usinas atualmente existentes encontram-se predominantemente em áreas que não possuem restrições importantes, o que comprova a coerência do modelo proposto. A ocupação da região Amazônica e do Pantanal mato-grossense, por exemplo, seria inviabilizada pela legislação ambiental, que protege estes compartimentos territoriais de forma bastante clara. Na faixa litorânea, as condições clinográficas predominantes dificultariam a mecanização de operações como a sulcação e colheita, uma tendência irreversível do setor para atender às exigências de eliminação da queima dos canaviais. No sertão nordestino, há sérias deficiências hídricas, cuja compensação exigiria investimentos demasiadamente elevados, o que também permite descartar a sua ocupação num primeiro momento. Da mesma forma, a região Sul encontra-se excessivamente exposta a geadas, que poderiam comprometer a produção. Estas restrições, somadas à enorme concentração espacial das unidades produtivas em terras paulistas, criaram dois vetores preferenciais de ocupação: 1) Triângulo Mineiro / Cerrado goiano e 2) norte do Paraná / Mato Grosso do Sul. Estas áreas, além de atenderem aos critérios de seletividade espacial propostos, ainda possuem a enorme vantagem da contiguidade em relação a São Paulo, sede dos principais grupos usineiros, das indústrias de bens de capital e serviços associados, dos centros de biotecnologia e destino da produção encaminhada à exportação. Deste modo, o direcionamento da expansão pautado em características naturais das regiões candidatas sofre, ainda, forte influência da presença de infraestruturas que viabilizem o escoamento da produção. Com isto, dentro das áreas de ocupação preferencial, aquelas contempladas com projetos visando a melhoria da integração multimodal têm total prioridade, como é possível observar na figura 2. 


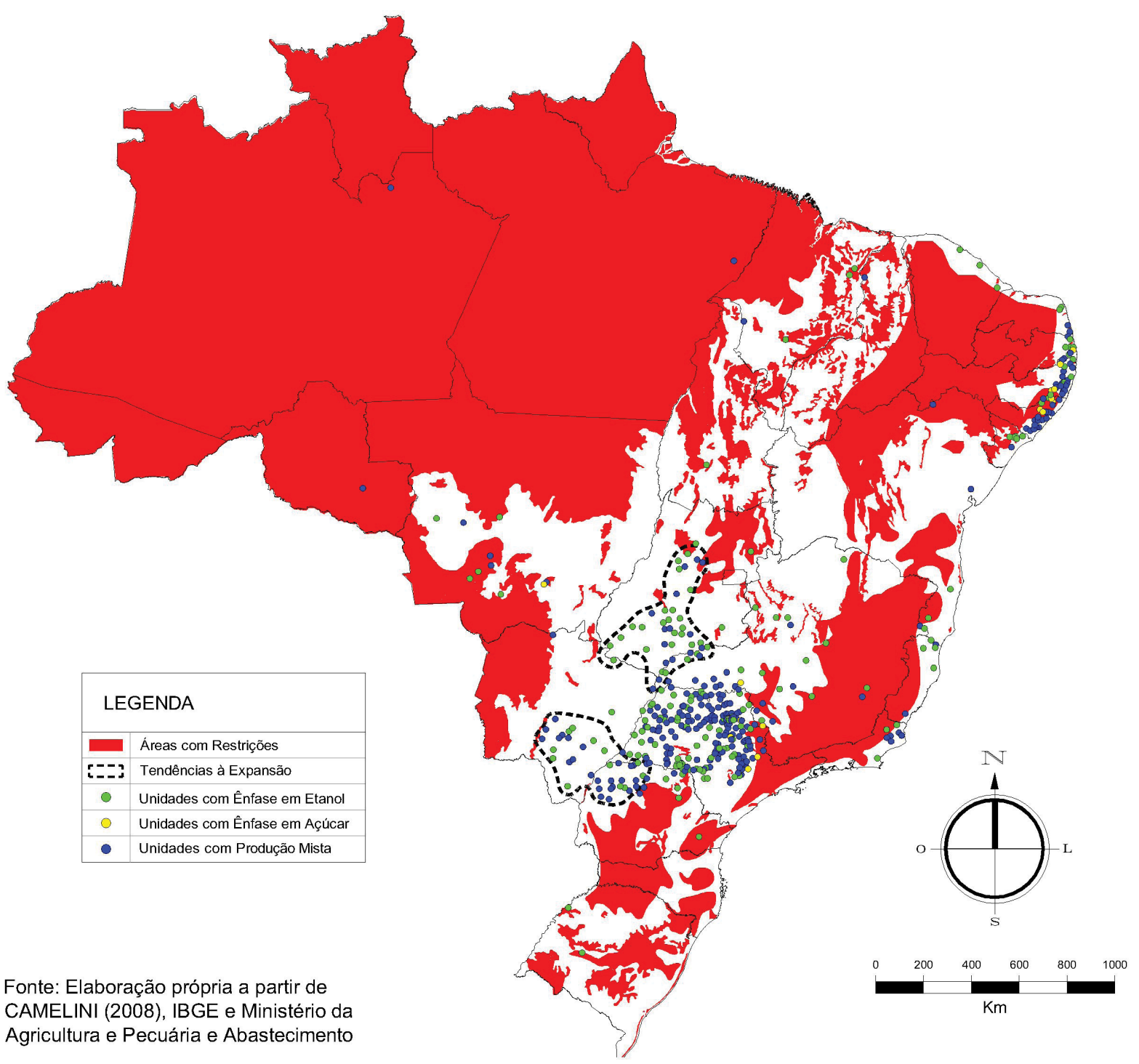

Figura 1 - Áreas com restrições ao avanço e ênfase produtiva das unidades atualmente existentes

O transporte por meio de dutos, cuja aplicação é ideal para o caso do etanol, requer um volume mínimo para que o retorno do investimento na sua construção se torne economicamente viável, o que leva necessariamente à formação de clusters de usinas nas suas proximidades. Recorrendo novamente à figura 1, é possível observar que as usinas que se encontram nas regiões de expansão priorizam oficialmente a produção de etanol. Aquelas que apresentam produção mista tendem a reverter grande parte do potencial produtivo para o etanol assim que isto se tornar economicamente interessante, quando da consolidação dos corredores planejados. Há que se reconhecer, também, que a existência de outros modais integrados atribui grande atratividade a uma região. $O$ eixo central de Goiás, por exemplo, oferece a possibilidade futura de transporte por meio da Ferrovia Norte-Sul, que poderá ter um terminal de cargas em Quirinópolis, a nova centralidade do etanol no Cerrado goiano (CAMELINI, 2011). 


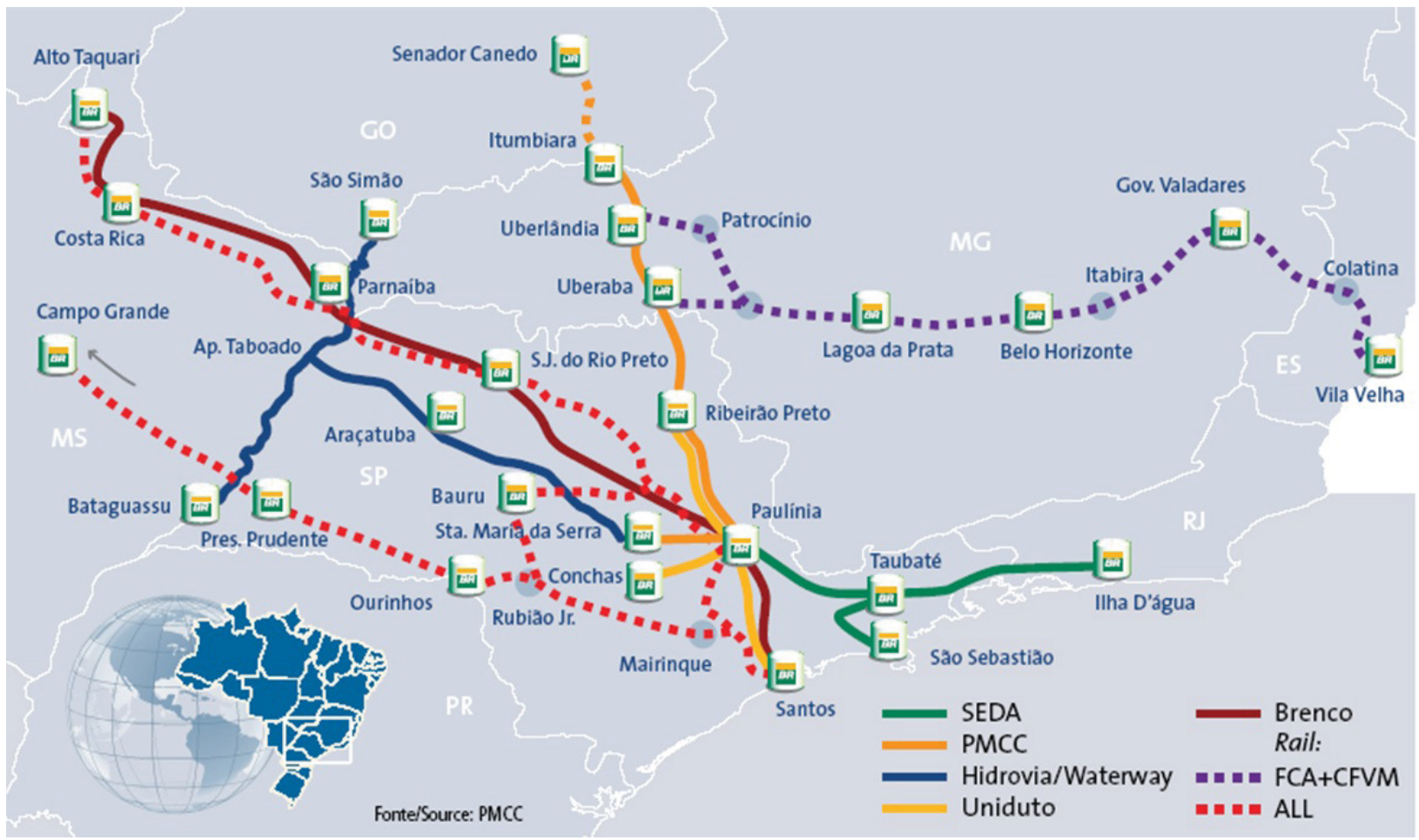

Figura 2 - Projetos de corredores para escoamento de etanol Fonte: PMCC, 2010

Todos estes fatos denotam a importância da logística no contexto atual, como fator de direcionamento dos fluxos materiais e reordenamento dos usos do território, e reforça a necessidade de sua plena compreensão do ponto de vista geográfico, segundo o qual ela pode ser descrita como

O conjunto de competências infra-estruturais (transportes, armazéns, terminais intermodais, portos secos, centros de distribuição etc.), institucionais (normas, contratos de concessão, parcerias público-privadas, agências reguladoras setoriais, tributação etc.) e estratégicas/operacionais (conhecimento especializado, detido por prestadores de serviços ou operadores logísticos) que, reunidas num subespaço, podem conferir fluidez /.../ e competitividade aos agentes econômicos e aos circuitos espaciais produtivos. (CASTILLO, 2007, p. 37)

Disto decorre que a competitividade regional para a produção de etanol encontra-se inexoravelmente condicionada à fluidez e que a adequada disponibilidade das competências envolvidas depende, fundamentalmente, da cooperação do Estado. Este se faz presente em diferentes etapas do circuito espacial produtivo (CASTILLO; FREDERICO, 2010a), solucionando "gargalos logísticos" através da execução e conservação de infraestruturas, do financiamento de grandes obras e do planejamento regional, que em última análise estimula investimentos privados. Dentro do modelo de regulação vigente, pode-se afirmar que este é o principal mecanismo de atuação estatal no direcionamento da expansão.

\section{COMPETITIVIDADE REGIONAL E VULNERABILIDADE TERRITORIAL ASSOCIADAS À PRODUÇÃO DO ETANOL}

A questão essencial relacionada à atuação do Governo Federal na regulação do setor sucroenergético reside na sua incapacidade de gerenciar as diferentes densidades normativas existentes no território nacional que, associadas a políticas de incentivo particulares de cada estado da federação e de cada município, geram uma disputa pela preferência dos grupos usineiros, baseada na concessão, por vezes irresponsável, de benefícios fiscais. Esta "guerra entre os lugares" perturba a solidariedade 
federativa e favorece o uso corporativo e não soberano do território (SANTOS, 2002). Com isto, a competitividade, anteriormente associada exclusivamente às empresas ou atividades econômicas, passa a ser também um atributo espacial (CASTILLO; FREDERICO, 2010b) e advém, dentre outros fatores, da sobreposição de incentivos nos planos federal, estadual e municipal. Deste modo, toda a complexa combinação de fatores envolvidos na seletividade espacial para o setor sucroenergético resulta na instalação de destilarias em pontos estratégicos do território, sob a ótica corporativa. $\mathrm{Na}$ maioria dos casos, é inevitável o surgimento de uma série de implicações locais, que decorrem da maneira com que se dá a ocupação, uma vez que esta é obediente a parâmetros externos, que dizem respeito às demandas do mercado, sendo totalmente alheios à realidade das regiões ocupadas. Isto é esperado, já que a natureza corporativa desta atividade não é caracterizada por comprometimentos com os interesses da população, o que é atribuição exclusiva do Estado. Disto resulta a concepção de vulnerabilidade territorial associada à produção de etanol, que pode ser interpretada como

a fragilização espacial decorrente da especialização para a produção de etanol que, por um lado, confere atributos de competitividade diferenciados para este segmento específico de atuação enquanto, por outro, diminui a autonomia local, à medida que insere o município num contexto de produção global, dentro do qual ele se torna extremamente funcional e alienado. Como resultantes deste processo, podem ser observadas diversas manifestações potencialmente comprometedoras da qualidade de vida, que decorrem da interferência direta ou indireta de agentes e processos totalmente desvinculados da realidade local. (CAMELINI, 2011, p. 58).

Na verdade, não há contradição entre a presença de atributos diferenciados de competitividade em relação a uma atividade economicamente promissora e a existência de potencial para desestruturação local. Ocorre que, em decorrência do surgimento de fluxos especializados, ligados a uma atividade produtiva específica, toda uma região pode se mobilizar com o objetivo de atender às suas demandas. Assim, para o caso do etanol, o urbano se torna funcional ao rural, resultando nas chamadas "cidades do agronegócio" (ELIAS, 2003; 2007), o que traz consigo uma série de implicações inseridas no contexto da ocupação, que serão discutidas a seguir.

O etanol é obtido através do processamento industrial de grandes quantidades de matéria-prima, que no caso do modelo brasileiro consiste na cana-de-açúcar. Diferentemente de outras culturas como a soja, cujos grãos podem ser armazenados por longos períodos (respeitadas algumas condições técnicas) ou transportados por grandes distâncias até o seu processamento industrial sem perdas consideráveis de propriedades, a proximidade com o centro de moagem é fundamental no que se refere à cana. Deste modo, para viabilizar custos e melhorar o aproveitamento dos atributos químicos da planta, esta deve ser colhida num raio aproximado de 40 quilômetros a partir do centro de moagem (SZMRECSÁNYI \& GONÇALVES, 2009), distância que varia a depender das condições logísticas existentes e do potencial produtivo dos solos disponíveis. Isto leva ao estabelecimento de quadros agressivos de ocupação, resultando invariavelmente na formação de imensas áreas sob o regime de monocultura, cujo gerenciamento depende da utilização dos recursos da chamada agricultura de precisão, sem os quais não seria possível obter rendimentos competitivos. Daí poder-se afirmar que a rigidez locacional associada à obtenção da matéria-prima para produção do etanol representa um fator de enormes implicações na estrutura agrária das regiões em que se realiza a produção.

Tendo em vista esta característica, figura 3 esboça uma tentativa de expressar a amplitude da influência do setor sucroenergético sobre o território brasileiro. Nele, fica estabelecido - de forma conservadora - que as unidades de processamento de cana irradiam sua influência para os municípios vizinhos àqueles em que se encontram instaladas, ocupando parcialmente suas terras, o que resulta em interferências diretas e indiretas no cotidiano local. 


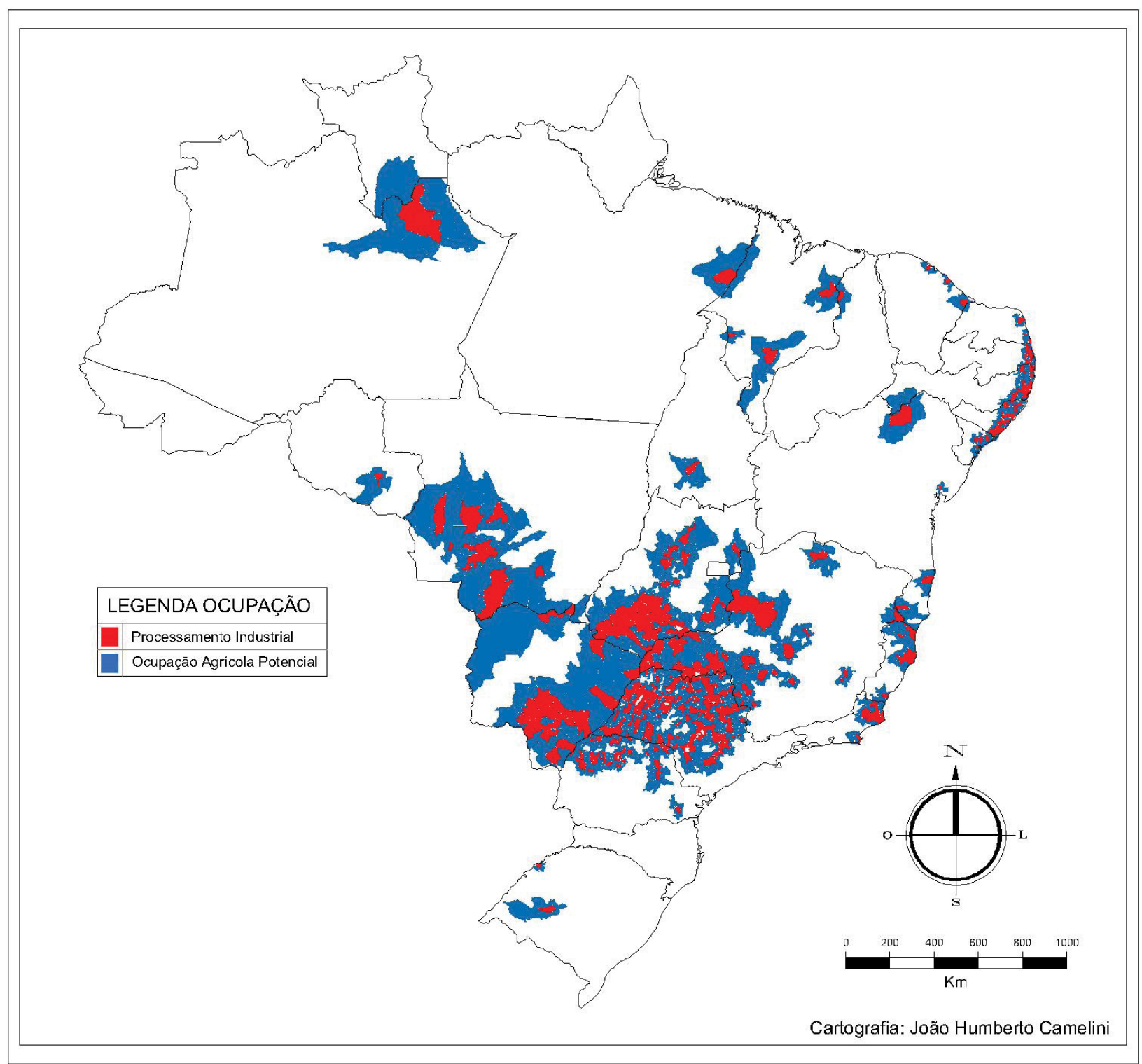

Figura 3 - Influência imediata da indústria sucroenergética

Fonte: CAMELINI, 2011

A agressividade da ocupação canavieira se faz sentir principalmente entre os pequenos produtores, que são envolvidos em esquemas de arrendamento aparentemente rentáveis para o proprietário da terra, mas que escondem armadilhas. Ocorre que, num primeiro momento, a remuneração por hectare é atraente, o que facilita o convencimento. O produtor passa, então, a viver nas cidades, utilizando esta renda para elevar seu padrão de vida. Tipicamente seduzido pelo consumismo, adquire veículos luxuosos como sinal de seu novo status social e, ao buscar inserção nas atividades urbanas, frequentemente emprega mal o restante do dinheiro devido à pouca experiência. Em relação à sua propriedade, quando se inicia o plantio de cana são destruídas cercas, casas, celeiros e quaisquer outras estruturas, de modo que esta perde suas características individuais e passa a integrar anonimamente o "mar de cana", tornando-se irreconhecível. Assim, somente será novamente demarcável através da execução de um levantamento topográfico que reproduza seu memorial descritivo. Com o passar dos anos, os contratos têm seus valores gradualmente reduzidos, tornando-se desinteressantes; no entanto, o investimento necessário para a retomada produtiva da terra não está ao alcance do proprietário, que percebe ter sido prejudicado, mas não tem outra alternativa senão continuar habitando os centros urbanos. Toda esta dinâmica é conhecida como "esquema para não voltar" (CASTILLO, 2009). Na realidade, mesmo aqueles que não querem ceder às ofertas de arrendamen- 
to acabam sendo forçados a isto, já que geralmente se tornam vítimas do mau cheiro da vinhaça, das queimadas e do ruído e vibração dos veículos, que circulam o tempo todo nas propriedades vizinhas. Sofrem, também, danos à saúde devido à contaminação da água e do ar por agrotóxicos.

A sistematização da ocupação canavieira é realizada a partir da perspectiva da mecanização de operações como a sulcação e a colheita. Assim, pensa-se na viabilidade da circulação dos veículos, enquanto acabam sendo deixados de lado os cuidados tradicionais com a conservação do solo, levando à compactação (pelo peso das máquinas) ou à erosão. Ademais, com o tempo, o uso intensivo de insumos para a produção contínua pode resultar em solos exauridos ou com excesso de sal. Estas formas de degradação, por vezes, dificultam, oneram ou inviabilizam economicamente a recuperação da terra para a atividade agrícola, mesmo dentro dos padrões de investimentos das grandes corporações. Isto representa uma perda considerável no longo prazo, especialmente para os municípios que dependem fundamentalmente da agricultura.

Embora seja alvo de muitos questionamentos, a mecanização é uma tendência aparentemente irreversível no campo. No caso específico da cana-de-açúcar, ela se apresenta como solução para a questão das queimadas, cuja prática vem sendo desestimulada nos últimos anos devido às pressões da legislação ambiental. A queima dos canaviais facilita a colheita manual, mas gera acidentes envolvendo trabalhadores e polui, multiplicando a quantidade de partículas em suspensão, o que resulta em diversos problemas de saúde entre os que habitam as proximidades. Além disto, o fogo destrói a camada superficial de microorganismos do solo, tornando-o empobrecido, e extingue grande parte da biodiversidade local, o que gera desequilíbrios ecológicos dificilmente reversíveis.

Ainda em relação à questão ambiental, é necessário ressaltar que o planejamento formal para a ocupação canavieira, em tese, respeita áreas de preservação ao longo dos rios e fragmentos de matas nativas. $\mathrm{O}$ que se observa na execução do plantio, porém, é que o desmatamento causado pela cana é direto e indireto. Direto, pois na prática ocorrem intervenções que ignoram as restrições documentadas no projeto de sistematização; indireto, porque a rigidez locacional das fontes de matéria prima faz a cana substituir agressivamente pastagens e culturas, como a soja, que acabam se deslocando para novas áreas, gerando desmatamento. Além disto, a falta de sintonia entre o projeto e a execução faz com que a cana seja plantada até a margem dos cursos d'água mais discretos, que com o tempo são assoreados. Existe, deste modo, grande perversidade na forma com que são executados os projetos de ocupação canavieira, o que torna ainda maior o desafio de apresentar uma solução que atenda às demandas industriais por matéria-prima sem resultar em tamanha pressão sobre o meio ambiente.

A manifestação local dos problemas associados à produção do etanol passa, também, pela delicada questão da força de trabalho no campo. Se, por um lado, a mecanização tende a eliminar grande parcela dos trabalhadores necessários para a colheita, ainda hoje há grande migração de cortadores de cana durante os períodos de safra. Estes trabalhadores vêm essencialmente do Norte e Nordeste em busca de ganhos adicionais e, para tanto, estão dispostos a grandes sacrifícios, como habitar alojamentos em condições sub-humanas e suportar as grandes pressões físicas e psicológicas por produção. Em alguns casos, a contratação por intermédio dos chamados "gatos" resulta até mesmo em trabalho infantil e escravo.

No cotidiano de alguns municípios em que a população é reduzida, o aporte migratório sazonal dos cortadores de cana impacta profundamente na estrutura dos serviços públicos, uma vez que o bóia-fria é ao mesmo tempo homem rural e urbano (SANTOS, 1988). O mercado imobiliário local se vê inundado por alojamentos improvisados, o que aumenta a especulação e causa a ocupação desordenada das cidades. Há complicações especialmente relacionadas ao sistema público de saúde, já que a rotina do corte de cana é dura e desgastante, exposta a acidentes, problemas respiratórios, complicações cardíacas, lesões por esforços repetitivos, danos à coluna cervical, entre outros. Segundo estudo realizado pela a Secretaria de Saúde de São Paulo, o trabalho representa uma perda diária de 8 litros de água, com o corte de 12 toneladas por pessoa, num esforço que envolve 170 
torções de dorso a cada dez minutos (ESTADO DE SÃO PAULO, 2011). Tudo isto exigiria uma compensação alimentar equivalente à de um atleta de alto rendimento, o que evidentemente não ocorre. Esta dinâmica das relações trabalhistas adotadas pelo setor sucroenergético transfere, pois, para a sociedade, uma série de consequências que derivam do seu modo de produzir e que, portanto, deveriam estar sob sua responsabilidade direta.

\section{CONSIDERAÇÕES FINAIS}

Dentre os fatores que direcionam a expansão da produção de etanol, parece claro que a presença de facilidades logísticas privilegiadas se configura num importante diferencial de atração, já que isto confere maior fluidez à circulação, o que, juntamente com outros critérios de seletividade espacial, como os benefícios fiscais, vem criando um veio preferencial de ocupação sobre algumas porções do Cerrado, notadamente o estado de Goiás (CAMELINI, 2011).

A ocupação canavieira é tradicionalmente dotada de características agressivas, que se devem, em grande parte, à rigidez locacional relacionada à obtenção de matéria-prima para a produção de etanol. Isto invariavelmente resulta no surgimento de ocupações dentro do regime de monocultura nas proximidades das usinas, o que ocasiona uma série de implicações na escala local, discutidas no presente trabalho. Ocorre que, para conferir competitividade ao produto final e justificar os investimentos realizados na construção de alcoodutos, deverão surgir áreas no Cerrado em que haverá grande concentração de usinas. Isto tornará uma porção imensa do território completamente funcional ao setor sucroenergético, uma vez que o adensamento de usinas implicará na sobreposição de áreas de influência sob o regime de monocultura.

Tendo em vista o caráter estratégico desta expansão e considerando que o Estado, por meio do BNDES, é um dos principais agentes financiadores de tais projetos logísticos (UDOP, 2010), torna-se evidente que há enorme parcela de responsabilidade do mesmo em relação à forma com que o uso corporativo do território se constrói. Isto demonstra, também, que o Estado possui, dentro do contexto regulatório vigente, mecanismos através dos quais pode exercer influência determinante sobre os rumos desta nova etapa da ocupação, de modo a preservar os interesses da população.

Por fim, é necessário enfatizar que a conversão do etanol em commodity é uma perspectiva bastante provável no presente momento. Sua realização depende, basicamente, do estabelecimento de um referencial de negociação. Este fato representará a unicidade da técnica (SANTOS, 1996) e também a primazia no mercado, entenda-se das empresas, na regulação do setor, tornando o etanol um produto efetivamente mundializado. A voracidade com que todos os processos aqui descritos ocorrem deverá se multiplicar, assim como os seus efeitos perversos. Com a diminuição das margens de lucro, somente os que produzirem muito terão condições de sobreviver pelo ganho de escala na produção, assim a tendência à oligopolização do setor se agravará, tornando-o ainda mais intensivo em capital. O mercado se tornará oligopsônico, subordinando totalmente o produtor, visto que também anulará completamente sua capacidade de negociação diante da imposição de preços internacionais. Causa preocupação a capacidade de reação econômica dos pequenos municípios dedicados ao setor diante das oscilações bruscas de preços, uma característica comum das commodities agrícolas. Enfim, é preciso que o processo de expansão da produção de etanol seja alvo de uma análise criteriosa, resultando num planejamento integrado, que possibilite a difusão homogênea dos benefícios ao invés da atual alienação das populações locais em relação ao uso, cada vez mais corporativo, dos territórios na escala municipal.

\section{REFERÊNCIA BIBLIOGRÁFICA}

CAMELINI, J. H. Análise combinada de planos de informação associados à expansão da cultura de cana-de-açúcar no território brasileiro. Monografia de Conclusão de Curso, Departamento de Geografia, Instituto de Geociências da Universidade Estadual de Campinas. Campinas, SP: [s.n.], 2008. 
CAMELINI, J. H. Regiões competitivas do etanol e vulnerabilidade territorial no Brasil: o caso emblemático de Quirinópolis, GO . Dissertação de Mestrado, Departamento de Geografia, Instituto de Geociências da Universidade Estadual de Campinas. Campinas, SP: [s.n.], 2011.

CANO, W. Prefácio. In: BRANDÃO, C. Território e desenvolvimento: as múltiplas escalas entre o local e o global. Campinas, SP: Editora da Unicamp, 2007.

CASTILLO, R. A. Agronegócio e Logística em Áreas de Cerrado: expressão da agriculturacientífica globalizada. Revista ANPEGE. V.3, p.33-43, 2007.

CASTILLO, R. A. Logística e consolidação de fronteiras agrícolas no território brasileiro: uma avaliação dos investimentos do governo federal em transportes de 1995 a 2005. Relatório final de pesquisa à Fundação de Amparo à Pesquisa do Estado de São Paulo (processo n. 2006/58008-3), inédito, 2009.

CASTILLO, R. A.; FREDERICO, S. Dinâmica regional e globalização: espaços competitivos agrícolas no território brasileiro. Mercator - Revista de Geografia da UFC, ano 09, número 18, 2010a.

CASTILLO, R. A. ; FREDERICO, S. Espaço geográfico, produção e movimento: uma reflexão sobre o conceito de circuito espacial produtivo. Sociedade \& Natureza, Uberlândia, 22 (3): 461-474, dez. 2010 b.

ELIAS, D. S. Globalização e Agricultura: a Região de Ribeirão Preto. 1. ed. São Paulo: EDUSP, 2003.

ELIAS, D. S. O meio técnico-científico-informacional e a reorgaznização do espaço agrário nacional. In: MARAFON, G. J.; RUA, J.; RIBEIRO, M. A. (Orgs.). Abordagens teórico-metodológicas em geografia agrária. 1 ed. Rio de Janeiro: EdUERJ, 2007, v. , p. 49-66.

ESTADO DE SÃO PAULO. Secretaria de Saúde. Saúde vai criar normas para melhorar condições de trabalho em canaviais de SP. São Paulo, 2011. Disponível em: http://www.saude.sp.gov.br/ses/noticias/2011/ janeiro/saude-vai-criar-normas-para-melhorar-condicoes-de-trabalho-em-canaviais-de-sp. Último acesso: 27 set. 2011.3

HARVEY, D. O Novo Imperialismo. São Paulo: Edições Loyola, 2004.

MARCOLIN, N. Era quase aguardente. Revista Pesquisa FAPESP. São Paulo: Fapesp, março 2008.

PMCC - Consórcio Petrobrás, Mitsui, Camargo Corrêa. Sistema Integrado de Escoamento de Etanol. Disponível em: http://2009.ethanolsummit.com.br/upload/palestrante/ 20090615045752937-654019145. pdf. Último Acesso: 10 fev. 2010.

PRADO JR, C. História econômica do Brasil. São Paulo: Brasiliense, 1961.

SANTOS, M. Metamorfoses do Espaço Habitado. São Paulo: Hucitec, 1988.

SANTOS, M. Guerra dos Lugares. In O País Destorcido: o Brasil, a globalização e a cidadania, São Paulo: Publifolha, 2002.

SANTOS, M. A natureza do espaço: técnica e tempo, razão e emoção. São Paulo: Hucitec, 1996.

SZMRECSÁNYI, T.; GONÇALVES, D. B. Efeitos Socioeconômicos e Ambientais da Expansão da Lavoura Canavieira no Brasil. Texto preparado para apresentação no Congresso de 2009 da LASA (Associação de Estudos Latino Americanos), no Rio de Janeiro, Brasil, de 11 a 14 de junho de 2009. Disponível em: http:/lasa.international.pitt.edu/members/congress-papers/ lasa2009/files/SzmrecsanyiTamas.pdf. Último acesso: 05 nov. 2009.

SZMRECSÁNYI, T.; MOREIRA, E. P. O desenvolvimento da agroindústria canavieira do Brasil desde a Segunda Guerra Mundial. Estudos Avançados 11(5), São Paulo: USP, 1991.

UDOP - União dos Produtores de Bioenergia. Primeiro alcooduto terá investimento do BNDES. Disponível em: http://www.udop.com.br/index.php?item=noticias\&cod=1071048. Último acesso: 23 nov. 2010.

UNICA - União da Indústria de Cana-de-açúcar, Anais Oficiais do Ethanol Summit 2009. Disponível em: http://www.unica.com.br/multimedia/publicacao/, Último acesso: 14 jan. 2011.

Trabalho enviado em maio de 2012

Trabalho aceito em junho de 2012 